\title{
FILOSOFIA, ÉTICA E EDUCAÇÃO: POR UMA CULTURA DE PAZ.
}

Viviane Catarini Paim ${ }^{1}$

Universidade de Caxias do Sul (UCS)

\section{EVERALDO CESCON/PAULO CÉSAR NODARI (ORG.). FILOSOFIA, ÉTICA E EDUCAÇÃO: POR UMA CULTURA DE PAZ. SÃO PAULO: PAULINAS, 2011.}

\begin{abstract}
"Assim como é possível erguer castelos de nuvens, na imaginação ou nos sonhos, na realidade do cotidiano também dá para se encarar a paz como o objetivo de um imenso e permanente canteiro de obras." (Clóvis Malta).
\end{abstract}

A paz apresenta-se como um termo, conceito ou definição, que perpassa o nosso dia a dia, geralmente, como um slogan que define a urgência de um mundo menos violento. Entretanto, a paz não é simplesmente a busca por uma utopia, mas a determinação de ações, a disposição dos sujeitos, a compreensão dos problemas de violência e exige, por sua vez, um processo educacional que possa efetivar uma cultura de paz.

A obra Filosofia, ética e educação: por uma cultura da paz, organizada pelos professores Everaldo Cescon e Paulo César Nodari, editada pela Editora Paulinas, em 2011, oferece, em 15 capítulos, uma rede de ideias e fundamentos em torno da paz. Na apresentação inicial, desenvolvem o conceito de paz e aprofundam, de maneira sólida, a definição de paz no seu sentido pleno. Trazem no seu conteúdo, as principais ideias que elucidam a totalidade da obra, apresentando as peculiaridades de cada artigo, ressaltando os autores, sendo que esses estão vinculados a diferentes instituições de Ensino Superior do Brasil e do Exterior. Dessa maneira, a apresentação inicial oferece um recorte de cada artigo da obra, já instigando os leitores a buscarem o seu conhecimento.

A obra pretende refletir e debater, juntamente com a comunidade acadêmica, a possibilidade de instaurar a paz, tendo a educação como meio para tal propósito. Tem como principal objetivo fazer da paz um objeto de investigação, no sentido de que ela necessita ser compreendida na sua totalidade, e isso significa entendê-la como um

\footnotetext{
${ }^{1}$ Mestranda no Programa de Pós-Graduação em Educação da Universidade de Caxias do Sul (UCS), Rio Grande do Sul - Brasil. E-mail: vcatarinip@gmail.com
} 
processo permanente, uma construção possível de ser atingida: “A paz é um processo progressivo, ainda que inatingível em sua plenitude. A paz não é, por conseguinte, um conceito estático." (p. 6). Além disso, a obra tem o intuito de traçar uma ciência da paz. "A cultura de paz exige uma busca criteriosa acerca de seus fundamentos, pressupostos e objetivos, constituindo-se, por conseguinte, como uma ciência da paz." (p. 19, grifos do autor). Ciência, no sentido de resolver os problemas e questões e compreender as causas que, nesse caso, referem-se à inclinação do ser humano à violência e/ou a disposição para a paz.

Alguns textos que conglomeram a obra, em especial o primeiro e o segundo artigos, do primeiro bloco, ${ }^{2}$ trazem argumentos fundamentados em pensadores como Kant, que defende a paz como um projeto de construção da razão, não sendo a paz algo natural, mas que necessita ser instaurada. No primeiro artigo, intitulado "Educação e cultura da paz: à luz do esboço kantiano À Paz Perpétua [Zum ewigen Frieden], ainda é possível pensar uma cultura da paz?", encontramos uma breve descrição dos conceitos de paz atribuídos por outros pensadores antes de Kant, mas que auxiliam a compreender que Kant tornou-se o pensador ideal em se tratando de uma cultura da paz: "O objetivo do direito kantiano é fundar a justiça e a paz como alicerce e garantia à vida de cada ser humano." (p. 26). Da mesma maneira, o segundo artigo, que tem como título "A paz perpétua e a educação: uma análise sobre o projeto kantiano" objetiva refletir sobre uma educação para a paz, tendo como textos fundantes À Paz Perpétua e Sobre a Pedagogia de Kant. Esse artigo descreve as ideias do referido autor sobre a paz entre os povos e as nações e realça a tarefa da educação para a efetivação dessa paz: "Sem educação não há paz.” (p. 56). Igualmente, caminha em direção à tarefa da família e da escola que é a de proporcionar os meios para uma educação voltada para a paz.

No segundo bloco da obra, aparecem, para fundamentar as reflexões, autores como Emmanuel Levinas (terceiro artigo), Jürgen Habermas (quarto artigo), Maurice Blondel (quinto artigo), Alasdair MacIntyre (sexto artigo) e Hannah Arendt (sétimo artigo). Todos esses pensadores estabelecem um aprofundamento das ideias, que circulam nos artigos apresentados no segundo bloco, o qual objetiva versar sobre os meios, os aspectos e os elementos que são necessários para a construção da paz. Isso implica educação como um propósito prático de busca de um projeto de construção da paz, combatendo o individualismo, a violência e buscando ações que visem ao alcance da cultura da paz. Temos, como exemplo desses elementos, a Teoria do Agir Comunicativo, de Habermas, referenciado no quarto artigo, intitulado "Cultura urbana e educação como desafios à teoria de Habermas do agir comunicativo"; escutar atenciosamente o outro e a sabedoria em construir um mundo possível, explicitado no terceiro artigo intitulado "Ética e alteridade: a educação como sabedoria da paz"; a abertura ao outro, o respeito à diversidade, o cultivo do sentimento de humanidade, que

\footnotetext{
${ }^{2}$ Bloco foi a divisão sugerida pelos organizadores da obra, e a explicação encontra-se na apresentação inicial do livro.

Filosofia, ética e educação: por uma cultura de paz - Viviane Catarini Pain

Everaldo Cescon/Paulo César Nodari (Org.). Filosofia, ética e educação: por uma cultura de paz. São Paulo: Paulinas, 2011.
}

Griot - Revista de Filosofia, Amargosa, Bahia - Brasil, v.3, n.1, junho/2011. 
são explicitados no quinto artigo: "Luta pela civilização: condições e exigências de uma educação da humanidade para a paz em Blondel"; combate ao individualismo, à violência, à destruição da genuína autonomia dos agentes morais, bem como cultivar a paz (virtude pessoal) estão referenciados no sexto artigo: "A paz como uma virtude? Algumas reflexões sobre educação e moralidade na filosofia de Alasdair MacIntyre"; pensar a paz como oposta à guerra, buscar a paz pela e com a política, resolver os conflitos via diálogo são elementos expostos no sétimo artigo, intitulado "Hannah Arendt e a questão da paz".

Já no terceiro bloco da obra, os artigos têm como propósito refletir sobre a cultura da paz, apresentando, desse modo, alguns modelos e exemplos que podem ser postos em prática para a efetivação de uma cultura da paz e, assim, desenvolver também uma educação para a paz. No oitavo artigo da obra, intitulado "Multiculturalismo, educação e paz", o autor enfatiza o multiculturalismo, defendido por alguns estudiosos, como uma doutrina política possível de resolver os conflitos a favor da paz social. Desse modo, o autor chama a atenção para a educação multicultural inclusiva, que seria uma forma de incluir membros de grupos minoritários na sociedade, construindo sua história dentro da história e, dessa maneira, reduzir a discriminação. No nono artigo, nos deparamos com a relação entre a "Educação para a paz e novas tecnologias", no qual são citados vários movimentos existentes no mundo acerca da promoção da paz: "Assim, a paz é vista como um processo em ação e um grande movimento em curso, muito mais do que uma meta a ser alcançada." (p. 250). A obra ressalta que, no momento em que vivemos, torna-se urgente a promoção de uma cultura da paz. Para tanto, é necessário uma educação para a paz. E a partir daí, refletir sobre a contribuição das novas tecnologias para esse contexto no qual estamos vivendo e para esse tipo de educação. São reforçadas as ideias de Habermas e Arendt ao defender o uso da palavra (ação comunicativa) como forma de resolver conflitos e, assim, abrir-se para uma perspectiva de educação para a paz. $\mathrm{O}$ autor atenta para alguns métodos de educação para a paz e, a partir desses elementos metodológicos, compreender como as novas tecnologias podem contribuir para a paz, no momento em que oportunizam formas de não violência, de críticas à violência e quando oferecem temas ligados à cultura da paz.

O quarto bloco da obra apresenta algumas críticas e dificuldades que a sociedade atual enfrenta, principalmente, na fundamentação filosófica dos direitos humanos, sendo que a sociedade é plural, global e necessita de uma convivência pacífica e de uma concepção política de justiça, para que os direitos humanos se efetivem. O décimo artigo nos apresenta uma reflexão acerca da ação humana, nos levando a pensar sobre o poder do homem sobre a natureza, sobre a manipulação dos recursos naturais, bem como o consumo desenfreado da população, que gera, cada vez mais, o poder do homem sobre o meio ambiente. Esse artigo, intitulado "Ética da reconciliação universal como condição da paz verdadeira", revela alguns desafios, que ainda temos que superar para alcançar uma verdadeira condição de paz. O autor defende o desenvolvimento sustentável, ao 2011

Griot - Revista de Filosofia, Amargosa, Bahia - Brasil, v.3, n.1, junho/2011. 
mesmo tempo que enfatiza que, com o crescimento exacerbado do consumo, torna-se difícil a possibilidade de conciliação entre produção material e respeito aos bens naturais. Para isso, é essencial uma responsabilidade ética e coletiva, levando em consideração uma ética universalista.

O desafio fundamental de nosso engajamento no mundo hoje tem, portanto, como pressuposto básico a fundamentação de um horizonte universalismo ético de bens e valores, ou seja, a superação da redução da ética à esfera do privado e arbitrário através da fundamentação racional de uma ética universalista, não utilitarista, mas ontológica, que lhe fornece os fundamentos racionais de um novo humanismo, capaz de enfrentar os desafios específicos à nossa época. (p. 312).

Já, no artigo, "Fundamentação dos direitos humanos e paz", outro desafio está imposto: a divergência entre juristas e filósofos quanto à validade universal dos direitos humanos. O autor apresenta três modelos de fundamentação (Habermas, K.-O. Apel e Vittorio Hösle). A partir desses, expõe a relação entre fundamentação e direitos humanos. Em se tratando de direitos humanos, o décimo terceiro artigo da obra retrataos no âmbito da educação. Traz como título "Direitos humanos na educação: superar os desafios" e reforça a necessidade de educar a sociedade em um processo de humanização que só é possível via educação, ou seja, a linha norteadora da educação em direitos humanos visa a "através dos valores humanos, internalizar e solidificar os princípios de cuidado, zelo e proteção da humanidade do outro". (p. 373). Entretanto, o texto indica algumas dificuldades encontradas, principalmente no ambiente escolar, no qual se presenciam aspectos ideológicos e sectários, que acabam impedindo as discussões e esclarecimentos a respeito dos direitos humanos. Nesse sentido, defende a disciplina de filosofia como promotora do esclarecimento ${ }^{3}$ dos indivíduos. O processo educativo escolar deve propiciar aos jovens a compreensão de conceitos que levem a ações humanas e justas, ou seja, à compreensão de valores como respeito, tolerância e paz.

No décimo segundo artigo, nos é apresentada a teoria rawlsiana sobre a justiça. $\mathrm{O}$ artigo intitula-se "Rawls e a prioridade do justo sobre o bem". Para Rawls, "numa sociedade democrática o justo e o bem se harmonizam". (p. 361). Ambos se complementam, desde que o bem respeite os contornos da justiça, sendo que a melhor forma de organizar a sociedade democrática é pela teoria política de justiça.

O justo é o que possibilita o cidadão a ser autônomo, por isso, se fala, em Rawls, de uma autonomia política. O cidadão, contudo, pode desenrolar sua vida sob uma concepção do bem, mesmo sabendo que o justo é anterior e

\footnotetext{
3 A palavra esclarecimento é utilizada sem um referencial teórico que fundamente este conceito. Esclarecimento, nesse sentido, dá ideia de esclarecer e viabilizar intelectual e humanamente os sujeitos. (p. $375)$.

Filosofia, ética e educação: por uma cultura de paz - Viviane Catarini Pain Everaldo Cescon/Paulo César Nodari (Org.). Filosofia, ética e educação: por uma cultura de paz. São Paulo: Paulinas, 2011.
}

Griot - Revista de Filosofia, Amargosa, Bahia - Brasil, v.3, n.1, junho/2011. 
possua primazia. Uma teoria política de justiça é, pois, a melhor forma de organizar uma sociedade democrática. (p. 371).

O último bloco do livro proporciona aos leitores conhecer a relação existente entre paz e religião, enfatizando o fundamentalismo religioso e a paz. A ênfase se dá na religião como uma das formas de nos orientarmos existencialmente. No décimo quarto artigo, intitulado "O fundamentalismo religioso e a paz", busca definir o termo fundamentalismo, explicitando que o mesmo retoma a religião como um poder primordial na sociedade contemporânea.

O "retorno ao papel político das religiões": o fundamentalismo, em muitos aspectos, se configura como a retomada de um tema que parecia eliminado da história contemporânea: voltar a falar de Deus e a pensar na sua Palavra (revelada ou não) num mundo que, por pudor ou indiferença, não mais o fazia. (p. 408).

Desse modo, a religião passa a assumir a função de integração social, ligada à política, à economia, à moral e à ciência. Passa o texto a explicar os principais fundamentos: o judaico, o cristão (Catolicismo, Protestantismo) e o islâmico. Por fim, discorre sobre o fundamentalismo religioso e a paz, acentuando que as teorias fundamentalistas acabam por gerar conflitos, entendendo que os diferentes defendem outros pontos de vista e opiniões. O artigo, ainda, ressalta, ainda, que somos iguais na dignidade, pois a dignidade é um dom de Deus. Desse modo, somos iguais em direitos e deveres e, por isso, o respeito deve prevalecer entre as pessoas, predominando a justiça e, assim, gerando a paz.

Para finalizar a obra, o décimo quinto artigo, em conformidade com o anterior, traz como título uma passagem bíblica "Bem-aventurados os construtores de paz" (Mt $5,9)$, pois, para o autor, a paz aproxima-se muito do termo bíblico shalom, que significa "um estado de bem-estar total, a harmonia do homem com Deus, com os outros, com a criação e consigo mesmo". (p. 445). Construir a paz é a sétima bem-aventurança em Mateus, que equivale a ações concretas dos homens, ou seja, aquele que deseja construir a paz deve ter disposição ativa para tal, exigindo, para isso, decisão dos indivíduos em prol do coletivo.

Após toda essa reflexão que a obra nos proporciona, fica claro que a busca de uma sociedade que detenha uma vontade de paz, valorizando sentimentos como respeito, dignidade, tolerância, para que, desse modo, se efetive a paz, a educação torna-se um meio indispensável na construção desta sociedade. Muitos são os desafios, principalmente nos meios escolares, nos quais se encontram grupos heterônomos, com uma gama diversificada de valores e princípios. Aos educadores resta a compreensão de que é urgente o retorno de um projeto educacional, que torne o sujeito responsável pela construção da paz, já que, nos tempos atuais, convivemos com e assistimos aos mais variados tipos de violência. A paz torna-se imprescindível à nova sociedade, que surge 2011. 
na contemporaneidade, e a educação, por sua vez, é o elemento essencial para a edificação dessa nova sociedade pautada em ações para a paz.

Filosofia, ética e educação: por uma cultura de paz - Viviane Catarini Pain Everaldo Cescon/Paulo César Nodari (Org.). Filosofia, ética e educação: por uma cultura de paz. São Paulo: Paulinas, 2011.

Griot - Revista de Filosofia, Amargosa, Bahia - Brasil, v.3, n.1, junho/2011. 